\title{
Traumatic Brain Injury Activation of the Adult Subventricular Zone Neurogenic Niche
}

\author{
Eun Hyuk Chang ${ }^{1}$, Istvan Adorjan ${ }^{2,3}$, Mayara V. Mundim ${ }^{4}$, Bin Sun ${ }^{2}$, Maria L. V. Dizon ${ }^{5}$ and \\ Francis G. Szele ${ }^{2 *}$ \\ ' Samsung Biomedical Research Institute, Samsung Advanced Institute of Technology, Samsung Electronics Co., Ltd., Seoul, \\ South Korea, ${ }^{2}$ Department of Physiology, Anatomy and Genetics, University of Oxford, Oxford, UK, ${ }^{3}$ Department of \\ Anatomy, Histology and Embryology, Semmelweis University, Budapest, Hungary, ${ }^{4}$ Department of Biochemistry, \\ Universidade Federal de São Paulo, São Paulo, Brazil, ${ }^{5}$ Department of Pediatrics, Prentice Women's Hospital, Northwestern \\ University Feinberg School of Medicine, Chicago, IL, USA
}

\section{OPEN ACCESS}

Edited by:

Luca Bonfanti,

University of Turin, Italy

Reviewed by:

Hans G. Kuhn,

University of Gothenburg, Sweden

Stefano F. Vecchioli,

Consiglio Nazionale delle Ricerche,

Italy

${ }^{*}$ Correspondence: Francis G. Szele

francis.szele@dpag.ox.ac.uk

Specialty section:

This article was submitted to Neurogenesis,

a section of the journal

Frontiers in Neuroscience

Received: 28 April 2016

Accepted: 30 June 2016

Published: 02 August 2016

Citation:

Chang EH, Adorjan I, Mundim MV,

Sun B, Dizon MLV and Szele FG

(2016) Traumatic Brain Injury Activation of the Adult Subventricular

Zone Neurogenic Niche.

Front. Neurosci. 10:332.

doi: 10.3389/fnins.2016.00332
Traumatic brain injury (TBI) is common in both civilian and military life, placing a large burden on survivors and society. However, with the recognition of neural stem cells in adult mammals, including humans, came the possibility to harness these cells for repair of damaged brain, whereas previously this was thought to be impossible. In this review, we focus on the rodent adult subventricular zone (SVZ), an important neurogenic niche within the mature brain in which neural stem cells continue to reside. We review how the SVZ is perturbed following various animal TBI models with regards to cell proliferation, emigration, survival, and differentiation, and we review specific molecules involved in these processes. Together, this information suggests next steps in attempting to translate knowledge from TBI animal models into human therapies for TBI.

Keywords: adult neurogenesis, stem cells, traumatic brain injury (TBI), regeneration, proliferation

\section{INTRODUCTION}

Traumatic brain injury (TBI) is a common problem with approximately 53,000 civilians dying from it annually in the United States alone and with as many as 5.3 million people living with TBI-related disabilities (Coronado et al., 2011; Kochanek et al., 2015; Rubiano et al., 2015). These numbers underestimate the impact as they do not include military casualties; the US Department of Defense reports 339,462 cases of TBI over the past 5 years (dvbic.dcoe.mil). TBI, also referred to as mechanical injury in this review, results in neuronal death often in the cerebrum, thereby producing several long-term and harmful symptoms including disturbances in memory, learning, attention, sleep, and motor coordination as well as the onset of headaches, fatigue, mood disorders, personality changes, and post-traumatic epilepsy (Rosenthal et al., 1998; Agrawal et al., 2006; Lowenstein, 2009; Hart et al., 2011).

For over a century, the writings of Cajal and other Nineteenth century neuroscientists instilled a dogma that the adult brain is incapable of replacing lost neurons. This belief was subverted when postnatal and adult stem cells in the mammalian subventricular zone (SVZ) and subgranular zone (SGZ) were rediscovered (Ihrie and Alvarez-Buylla, 2011; Spalding et al., 2013). While hippocampal SGZ neurogenesis is very interesting and especially relevant to the cognitive fluctuations in TBI, this review will focus on the SVZ as more information is known about its response to TBI and since SVZ progenitors migrate to injury sites (Young et al., 2011). The rodent SVZ replaces tens of thousands of olfactory bulb $(\mathrm{OB})$ interneurons daily. Adult Homo sapiens and non-human primates also 
exhibit SVZ neurogenesis with similarities as well as significant differences from rodents (Eriksson et al., 1998; Bernier et al., 2000; Weickert et al., 2000; Kornack and Rakic, 2001b; Pencea et al., 2001b; Sanai et al., 2004; Curtis et al., 2007; Kam et al., 2009; Wang et al., 2011; Bergmann et al., 2012; Ernst et al., 2014). Nonetheless, the proximity of the SVZ to the cortex and other vital forebrain nuclei raises the possibility that the neurogenic potential of SVZ stem cells and their migratory progeny may naturally contribute to endogenous repair (Dizon and Szele, 2005; Young et al., 2011). Moreover, SVZ stem cells might be induced to respond more robustly.

Different strategies have been considered for harnessing the therapeutic potential of SVZ cells (Young et al., 2011). Endogenous SVZ cells might be induced via molecular manipulation in situ to proliferate, emigrate to sites of injury, and differentiate into the types of cells lost to TBI (Yu et al., 2013). SVZ cells might also be manipulated in vitro and then transplanted to the needed areas after they have been expanded and transduced with gene constructs to direct cell fate (Lois and Alvarez-Buylla, 1993; Kukekov et al., 1999; Ostenfeld et al., 2002; Gil-Perotin et al., 2013). It is important to consider how TBI alters the SVZ in the context of both strategies (Dizon and Szele, 2005).

A key question is if de novo mechanisms come into play after injury, if extant mechanisms are altered, or if some combination of the two occurs. It is unclear to what extent the same or different molecular regulators affect SVZ proliferation, migration, or survival in homeostasis as after TBI. In this review, we attempt to identify knowledge gaps and propose potential novel approaches. The SVZ field has exploded in the last decade (Dizon and Szele, 2005), and we have attempted to include most of the recent TBIrelevant citations. We acknowledge that many studies on the SVZ after stroke, neurodegenerative diseases, and other disorders may be relevant to TBI, but are too numerous to discuss here. By virtue of its plasticity, the postnatal brain may be a better target for repair than the adult. We concentrated on adults as there is less data on the young SVZ niche response to TBI, and as the SVZ changes markedly throughout postnatal life so comparisons across ages are problematic.

The SVZ responses to TBI can occur immediately or last for years and include mechanical forces (immediate), hemorrhage (short-term), edema (medium-term), and gliosis (medium to long-term). Each of these phases is accompanied by, or caused by, distinct molecular and cellular changes, suggesting that the SVZ is tightly regulated after TBI. These distinct temporal changes should inform therapeutic strategies and the selection of target molecules within the windows of opportunity.

Each individual TBI model is complex not just because of its temporal but because of its regional, molecular, and cellular variability. Inconsistency in the sorts of injuries and animals used in TBI studies lead to further difficulty in interpreting the results (Table 1). Injuries that extend to and include the SVZ or the rostral migratory stream (RMS) result in extensively different responses than parenchymal TBI (Ramaswamy et al., 2005). While cortical aspiration, weight percussion, and fluid percussion models of TBI do not directly lesion the SVZ (Szele and Chesselet, 1996; Holmin et al., 1997; Chirumamilla et al., 2002; Goings et al., 2002; Chen X. H. et al., 2003), the resultant mechanical shocks may affect the neurogenic niche, which should be taken into consideration. We have shown that different injury models (aspiration vs. thermocoagulatory cortical lesions) directed at the same brain region cause variable attempts at endogenous repair, which emphasized the necessity of studying the SVZ after different types of TBI and in multiple species (Szele and Chesselet, 1996; Goings et al., 2002, 2006; Ramaswamy et al., 2005; Sundholm-Peters et al., 2005).

\section{MECHANICAL FORCES IN TRAUMATIC BRAIN INJURY}

TBI involves physical forces that likely influence SVZ neurogenesis, usually including immediate but transient increases in intracranial compression and lateral ventricle (LV) pressure. Later, hemorrhage can cause obstructive hydrocephalus with persistently increased LV hydrostatic pressure. Human hydrocephalus can tear the ependymal layer and cause astrocytosis (Bruni et al., 1985; Sarnat, 1995). Parenchymal edema with or without obstructive hydrocephalus produces persistently increased intracranial pressure. Brain tissue loss, in contrast, can decrease pressure and increase LV volume (Volpe, 1995; Reider et al., 2002). These, and a long list of other macro and micro mechanical forces, are all important considerations as an emerging literature shows that mechanical stresses induce distinct molecular events (Ingber, 1997, 2002; Grodzinsky et al., 2000; Keller et al., 2003; Guirao et al., 2010).

Mechanical forces cause $\beta$-catenin homolog Armadillo to translocate to the fly nucleus (Farge, 2003). Wnt signaling affects SVZ neurogenesis and gliogenesis (Azim et al., 2014a,b), and $\beta$-catenin inhibits neuronal progenitor cell cycle exit and thus expands the cerebral cortex (Chenn and Walsh, 2002). Similarly, mouse embryonic stem cells subjected to sheer forces of different magnitude and duration exhibited concurrent changes in pluripotency and the Wnt signaling pathway (Wolfe et al., 2012). Mechanical forces are likely to affect not only SVZ cells but also ependymal cells (EC) as CSF hydrodynamic forces are necessary for their development (Guirao et al., 2010).

ECs form the barrier to the ventricles and are strongly linked by tight junctions (Mitro and Palkovits, 1981). Similarly, SVZ cells are connected by specific cell surface molecules (Lois et al., 1996) and are surrounded by a thin ECM and basal lamina distinct from other brain regions (Miragall et al., 1990; Jankovski and Sotelo, 1996; Mercier et al., 2002). Thus, the mechanical properties of ECs, the SVZ, and the adjacent tissue are all probably different from one another. It is unknown if SVZ or EC adhesion or ECM following TBI alters stiffness and thereby contributes to ventricular enlargement after TBI (Reider et al., 2002; Chen X. H. et al., 2003). However, ventricular expansion can be modeled, thereby making these questions tractable (Iwamoto et al., 1997; Bramlett and Dietrich, 2002). Rat kaolininduced communicating hydrocephalus initially increased the number of SVZ nestin + cells followed by a decrease ( $\mathrm{Li}$ et al., 2014). The same model in ferret decreased SVZ Ki67+ cells in SVZ and increased SVZ caspase-3+ cells (apoptosis) (Di Curzio 


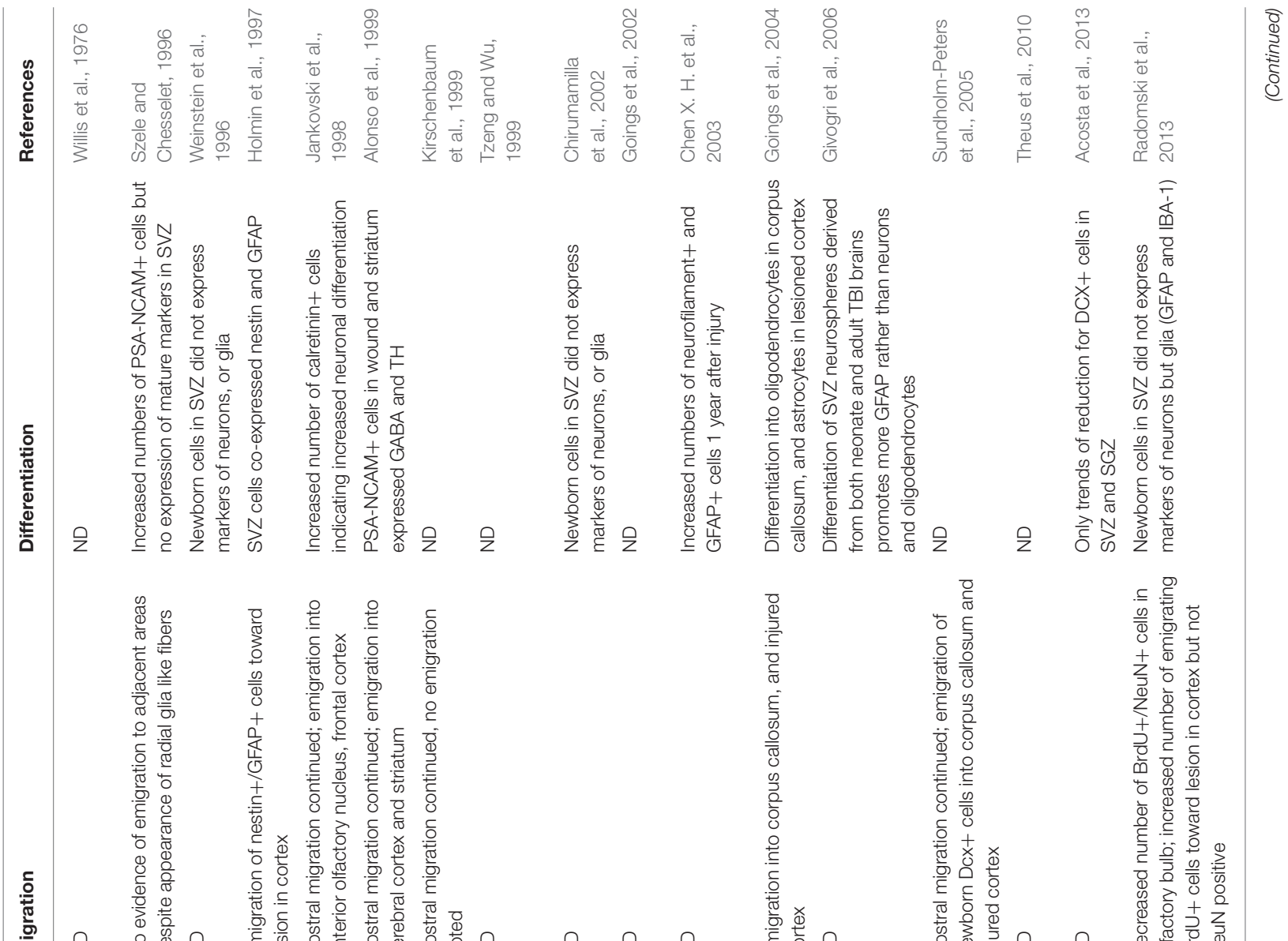

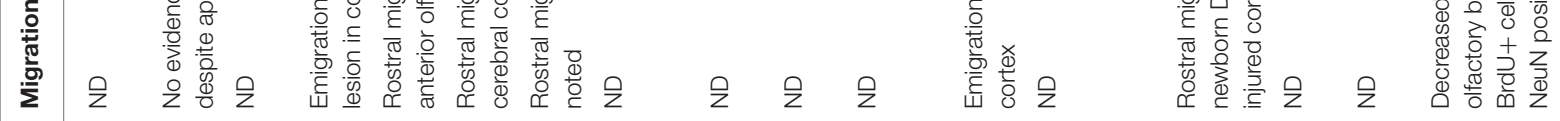

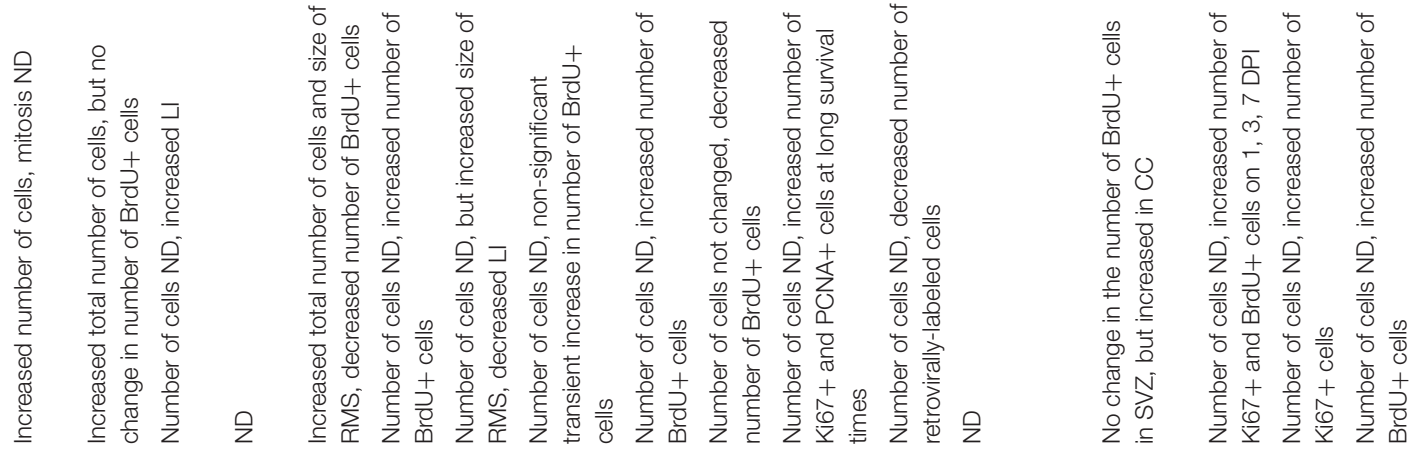

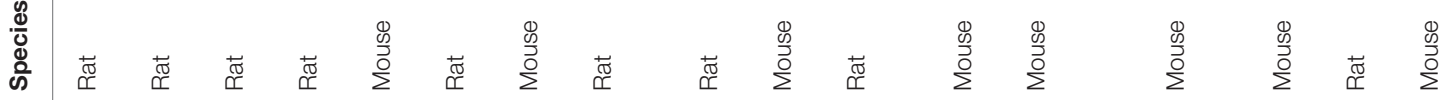

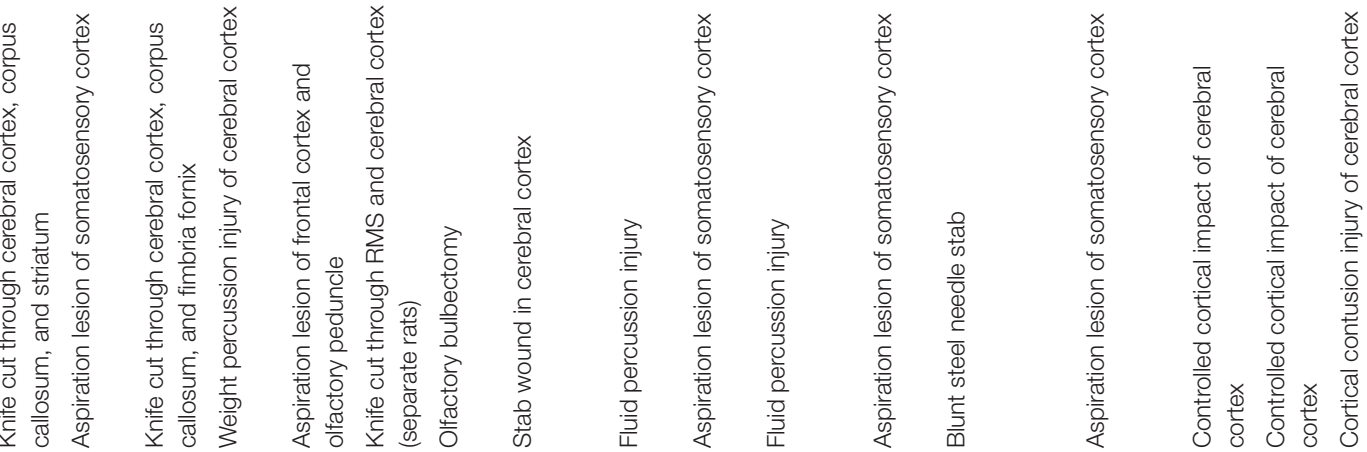


et al., 2013). Thus, future studies should be able to integrate post-TBI mechanical forces with molecular events.

\section{SVZ PROLIFERATION AND NEUROGENESIS GENERALLY INCREASE AFTER TRAUMATIC BRAIN INJURY}

Changes in cell numbers and proliferation in the SVZ after knife cut brain injury were already investigated in the mid-1970s in rat (Willis et al., 1976) and have been studied more often than other sequelae of TBI (Table 1). 5-Bromo-2'-deoxyuridine (BrdU) pulse studies at various time points after injury indicate the number of cells in S-phase and assume that the cell cycle will be completed and mitosis will occur. It is important to determine the percent of proliferating SVZ cells, or the "labeling index," as the final population of SVZ cells is ultimately determined by the combination of the labeling index, cell cycle length, emigration rates from the SVZ, and cell death. That is, more BrdU+ cells do not necessarily mean increased SVZ cell numbers. With these caveats in mind, a survey of the literature suggests that SVZ division and cell numbers increase after TBI although there are discrepancies amongst studies (Figure 1).

The following parameters are amongst the most crucial to consider in comparing different post-TBI SVZ proliferation studies: (1) species, (2) type of injury, (3) proliferative markers, and (4) survival time. Contradictory results can originate from the diversity of these parameters. Considering the survival time, a four-phase response to TBI may help explain apparent discrepancies across studies (Figure 1A). Within the first 5 days following TBI, SVZ proliferation in the adult rat is unchanged (Tzeng and Wu, 1999; Gotts and Chesselet, 2005; Goodus et al., 2015), thereafter proliferation is increased, peaking around the post-operative 7th day with a 100\% increase (Szele and Chesselet, 1996; Weinstein et al., 1996; Gotts and Chesselet, 2005; Sun et al., 2009, 2010; Bye et al., 2011) and subsequently returns to baseline by the end of the first month (Bye et al., 2011). More recently, the timepoint of 7 and 14 days after aspiration cortical lesions in rat was studied. A significant increase in BrdU+ cells ipsilateral compared to contralateral to the lesion was observed at 7 days, but this difference was lost by 14 days (Yang et al., 2010). Chronically, (8 weeks and on) baseline proliferation is further decreased by $\sim 50 \%$ after controlled cortical impact in rats (Acosta et al., 2013, 2014). These phenomena (Figure 1A) highlight the importance of careful interpretation of results that are often obtained from different survival periods.

In contrast to rat, a four-phase process cannot explain the discrepancies in mouse studies of SVZ proliferation post-TBI (Figure 1B). Most articles report increased SVZ proliferation following controlled cortical impact or aspiration lesion (Theus et al., 2010; Radomski et al., 2013; Saha et al., 2013; Thomsen et al., 2014). However, no change was found by the Armstrong group (Sullivan et al., 2013; Mierzwa et al., 2014), and the Szele group found a biphasic decrease that occurred in mouse in the first post-operative week and later in the fourth and fifth postoperative weeks (Goings et al., 2002). This decrease is similar to the observations of Jankovski and colleagues in mouse after lesion 

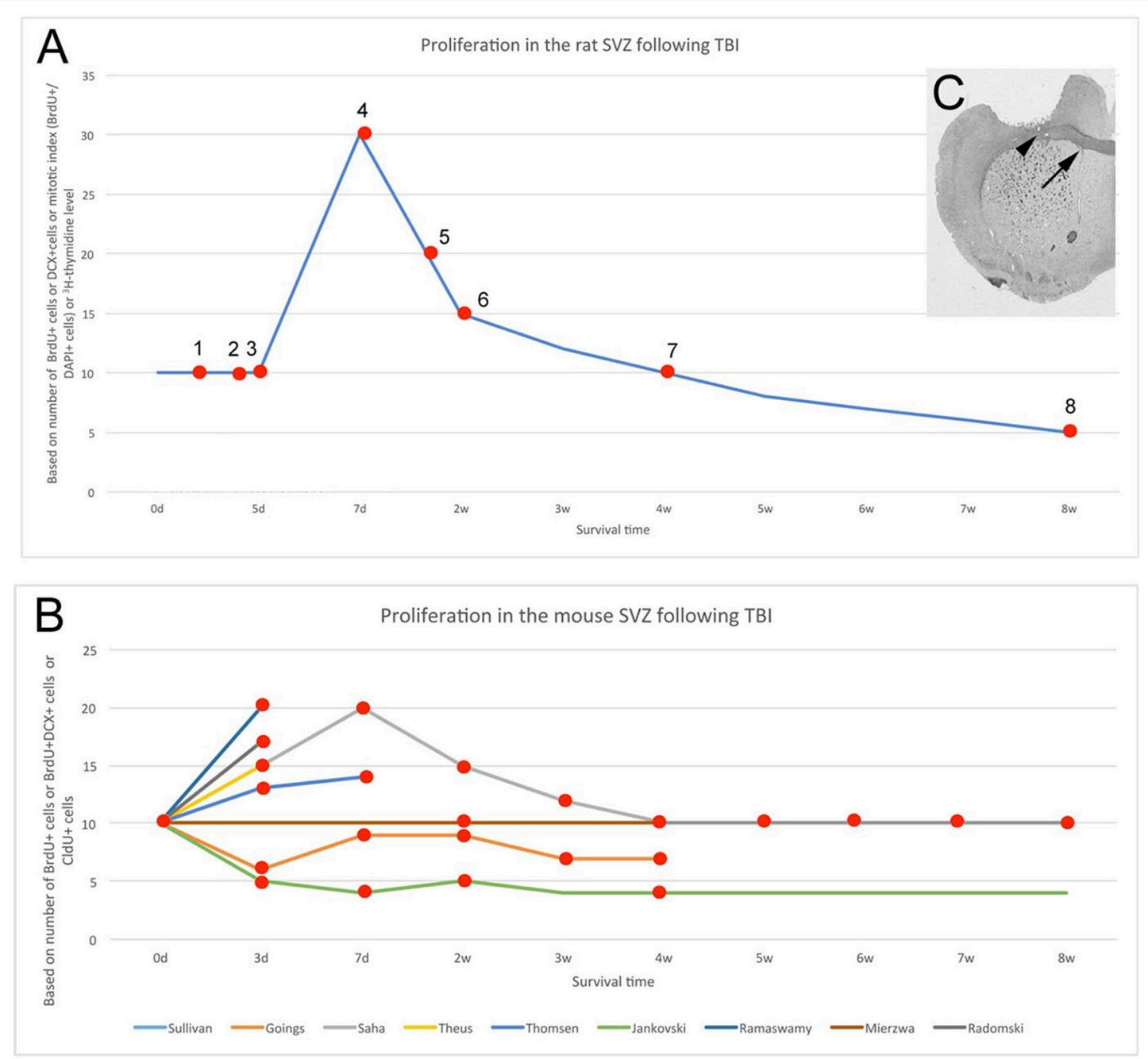

FIGURE 1 | Altered SVZ proliferation is variable across species and experiments. (A) Increased SVZ proliferation and/or neurogenesis in rat after mechanical injury to brain. Data from multiple studies. 1 - (Tzeng and Wu, 1999), 2 - (Goodus et al., 2015), 3 - (Gotts and Chesselet, 2005), 4 - (Szele and Chesselet, 1996; Sun et al., 2009, 2010; Bye et al., 2011), 5 - (Weinstein et al., 1996) 6, 7 - (Bye et al., 2011; Grande et al., 2013), 8 - (Acosta et al., 2013, 2014). For both (A,B), baseline was set at a value of 10 and percent changes from this are shown. (B) SVZ proliferation or neurogenesis in mouse after mechanical injury across multiple studies. Individual studies shown with colored lines (Jankovski et al., 1998; Goings et al., 2002; Ramaswamy et al., 2005; Theus et al., 2010; Radomski et al., 2013; Saha et al., 2013; Sullivan et al., 2013; Mierzwa et al., 2014; Thomsen et al., 2014). The Saha et al., study was the most complete including time points at 3 days, 1, 2, 3 , 4, 5, 6, 7, and 8 weeks post-lesion. (C). Cortical injury via aspiration. The injury excludes the corpus callosum (arrowhead) but is close to the subventricular zone (arrow). Aspiration lesions of the cerebral cortex were made in the same location both in mouse and rat (Szele and Chesselet, 1996; Goings et al., 2002, 2004).

of the cortex and olfactory peduncle (Jankovski et al., 1998). The reason for diverse responses of SVZ proliferation after injury was further investigated, and Radomski and colleagues clearly demonstrated in mouse that SVZ proliferation did not change after 3 days of a "mild" cortical impact (up to $1 \mathrm{~mm}$ depth) but "moderate" impact (up to $2 \mathrm{~mm}$ depth) caused a significant 60\% increase (Radomski et al., 2013). This example suggested that severity of injury affects the SVZ proliferation instead of injury timing (Figure 1B).

The extensively used fluid percussion model of TBI involves a controlled impact on the cerebral cortex surface (McIntosh et al., 1987; Chen S. et al., 2003; Chen X. H. et al., 2003; Prins and Hovda, 2003). This TBI model has several strengths such as the control of its size and location and is considered to be one of the best of non-penetrating TBI models. SVZ cell division was augmented at short time points after fluid percussion injury in rat (Chirumamilla et al., 2002). Another group found that control rats had significant age-related declines in PCNA+ and Ki67+ SVZ cell numbers, but this decline was blocked in fluid percussion-injured rats (Chen X. H. et al., 2003). This model is mostly been used in rat but has also been adapted to mice (Carbonell et al., 1998). We found more murine SVZ cells in $S$ phase after controlled cortical impact of the cortex (Ramaswamy et al., 2005). Penetrating brain injury models that do not impact the SVZ are similar to certain human brain injuries as well to brain surgeries/biopsies and thus deserve to 
be studied. Sagittal cuts through the cortex and fimbria doubled the number of cycling SVZ cells the rat SVZ (Weinstein et al., 1996). Stab wounds of the rat cerebral cortex did not alter BrdUincorporation in the SVZ (Tzeng and Wu, 1999); however, a similar needle stab in mouse induced a 2-fold increase in SVZ BrdU+ cells (Givogri et al., 2006). Thus, in comparison to more dramatic lesions, smaller injuries affect SVZ proliferation much less or not at all.

Considerable data have accumulated showing constitutive human SVZ proliferation. SVZ neurogenesis in the first 2 years after birth is widely accepted, but neurogenesis in the adult human SVZ is controversial. According to Sanai and colleagues, adult human neurogenesis is largely depleted along the SVZRMS-olfactory bulb axis after 18 months (Sanai et al., 2011). Nevertheless, it still seems to exist in at least a vestigial form, as Wang and colleagues found proliferation in the ventral SVZ and a small number of migrating DCX + cells in the RMS and olfactory tract in adult humans (Wang et al., 2011). In contrast, Frisen and colleagues did not find evidence for olfactory bulb neurogenesis but instead found evidence for proliferative SVZ cells as well as adult striatal neurogenesis by birth dating of neurons based on the detection of ${ }^{14} \mathrm{C}$ levels in the brain (Bergmann et al., 2012; Ernst et al., 2014). This creative technique may prove to be important in determining the human neurogenic response to TBI. Indeed, the same group showed that in Huntington's disease, the number of newborn neurons appeared to decrease (Ernst et al., 2014). It will be important to confirm or refute the ${ }^{14} \mathrm{C}$ studies to help understand the capacity of human neurogenesis to contribute to TBI brain repair.

Relatively few investigations have evaluated human SVZ proliferation following TBI. There was no increase in the number of DCX + migrating neuroblasts in the SVZ of children with TBI compared to non-TBI patients (Taylor et al., 2013). However, caution is warranted due to the small sample size (6 TBI vs. 7 non-TBI) and the short survival time (average $34 \mathrm{~h}$ ) examined. The one patient who survived 7 days in this study had the highest number of migrating neuroblasts, thereby indicating a need for future studies of longer term responses to TBI. Adult human patients following TBI exhibited increased numbers of DCX+, PSA-NCAM+, and SOX2+ cells (Zheng et al., 2013). Nonetheless, this study focused on the cortex and not the SVZ. Taken the aforementioned data together, a shift from rodent models to primate research and more post-mortem human studies are needed in order to understand the proliferative capacity of the human SVZ and to harness this potentially relevant endogenous resource for the repair of injured brain.

Despite over 100 therapies attempting to ameliorate TBI in rodents, none has been successfully translated to the clinic (Marklund et al., 2006; Margulies et al., 2009). This could be due to interspecies differences such as lissencephalic vs. gyrencephalic cortices: growth trajectory, cellular proliferation, and myelination (Costine et al., 2015). In searching for a better human SVZ model, neurogenic properties of other species have been described: rabbit (Luzzati et al., 2006), sheep (Liard et al., 2009; Brus et al., 2012; Low et al., 2013), pig (Liard et al., 2009), and non-human primate (Kornack and Rakic, 2001a; Pencea et al., 2001b; Bedard et al., 2002; Gil-Perotin et al., 2009).
However, these species have not been systematically investigated and their SVZ repair capacity is still unknown (with the exception of increased proliferation found in the immature piglet SVZ) (Costine et al., 2015).

\section{PROGENITOR CELLS MIGRATE FROM THE SUBVENTRICULAR ZONE TO TRAUMATIC BRAIN INJURY}

For stem cells to be of therapeutic value, they must move to or be placed into areas of injury. SVZ cells migrate to brain injuries to variable degrees, and this migration is regulated via several mechanisms (Young et al., 2011). Neuroblasts in the adult SVZ normally migrate to the OB in strings, which is termed as chain migration in the confined RMS. The RMS contains a network of specialized astrocytes (Jankovski and Sotelo, 1996; Lois et al., 1996) that guide neuroblast migration but are not absolutely necessary for their movement (Wichterle et al., 1997; Jacques et al., 1998). TBI induces both chain and individual cell migration out of the SVZ and RMS (Figure 2).

Classic studies showed that RMS transection causes SVZ cell accumulation posterior to the lesion and cell emigration into the lesioned cortex and striatum in mouse (Jankovski et al., 1998; Kirschenbaum et al., 1999) and rat (Alonso et al., 1999). When the PSA-NCAM+SVZ neuroblasts migrated to the lesion, they remained in their normal chain-like configuration (Lois et al., 1996). Removal of the OB resulted in continued rostral migration of SVZ cells (Jankovski et al., 1998; Kirschenbaum et al., 1999), although rostral migration is induced by OB chemoattractants (Liu and Rao, 2003; Ng et al., 2005). In a motor cortex aspiration TBI model in mouse (Figure 3), neuroblasts continued to migrate in chains after exiting the RMS and entering the corpus callosum, but as soon as they reached the cortex, they no longer migrated as chains (Saha et al., 2013). Most were found in close proximity or in contact with blood vessels

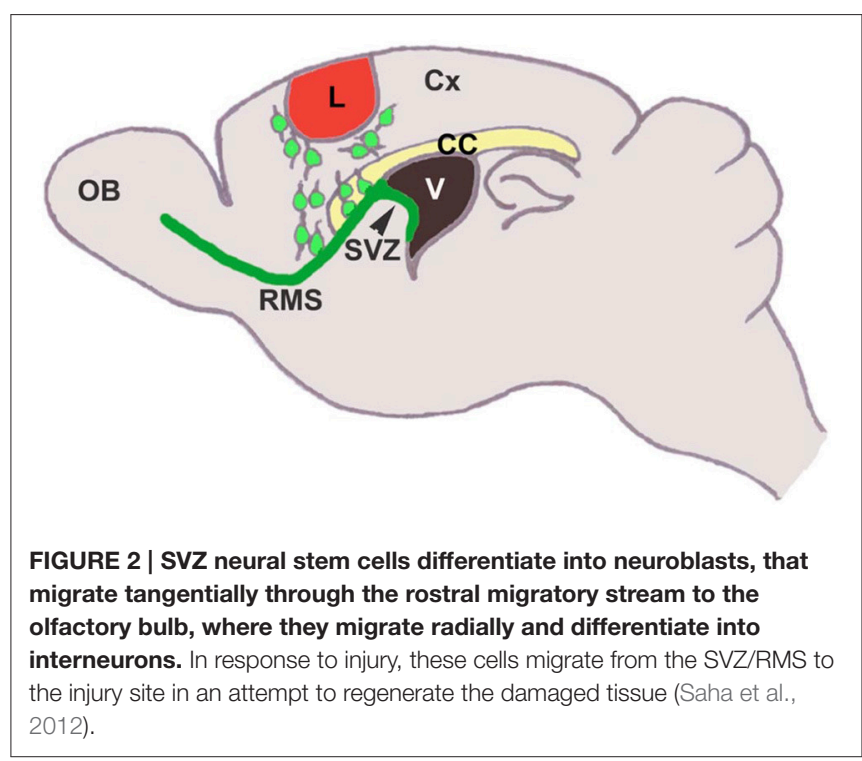



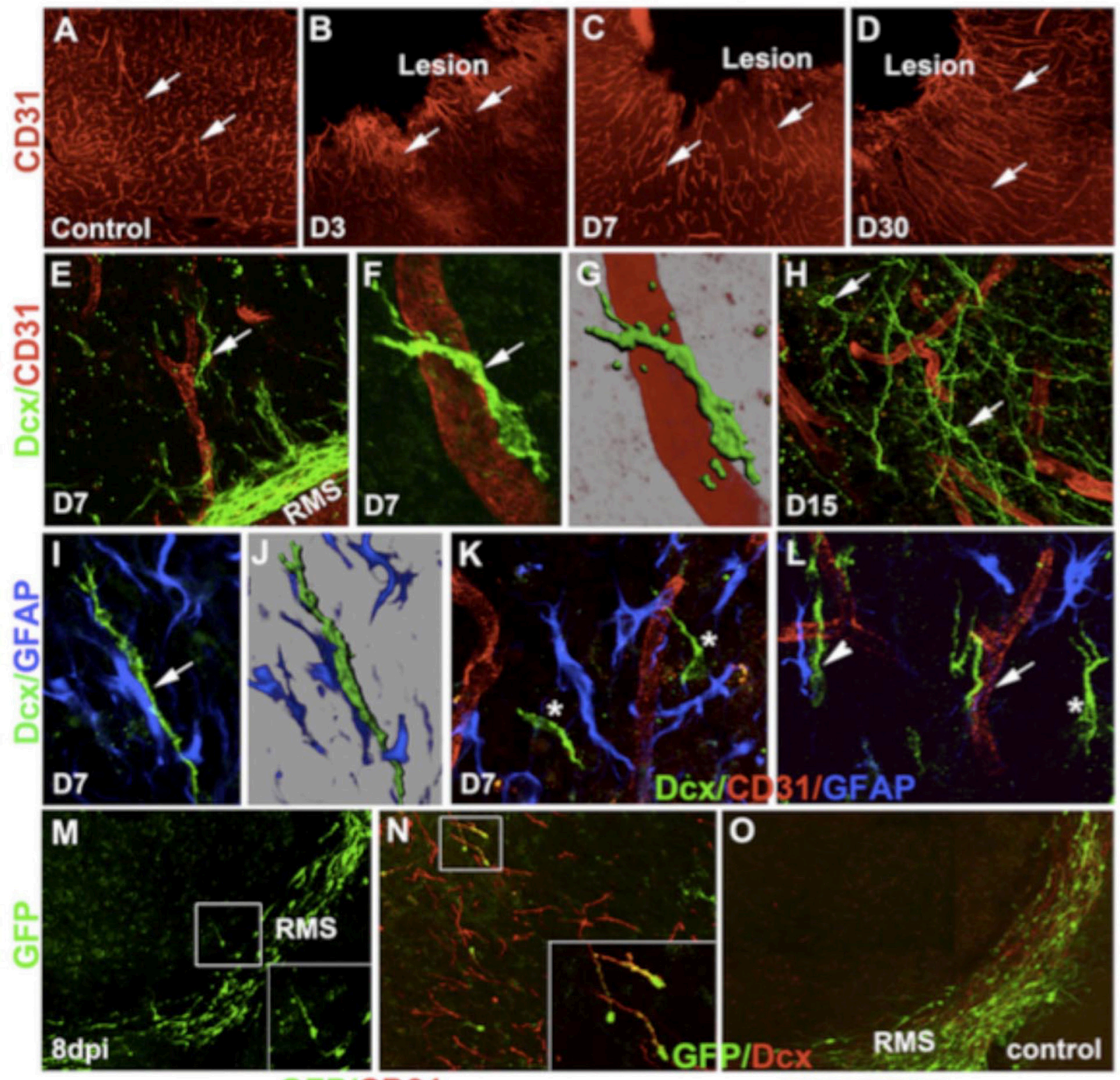

\section{GFP/CD31}
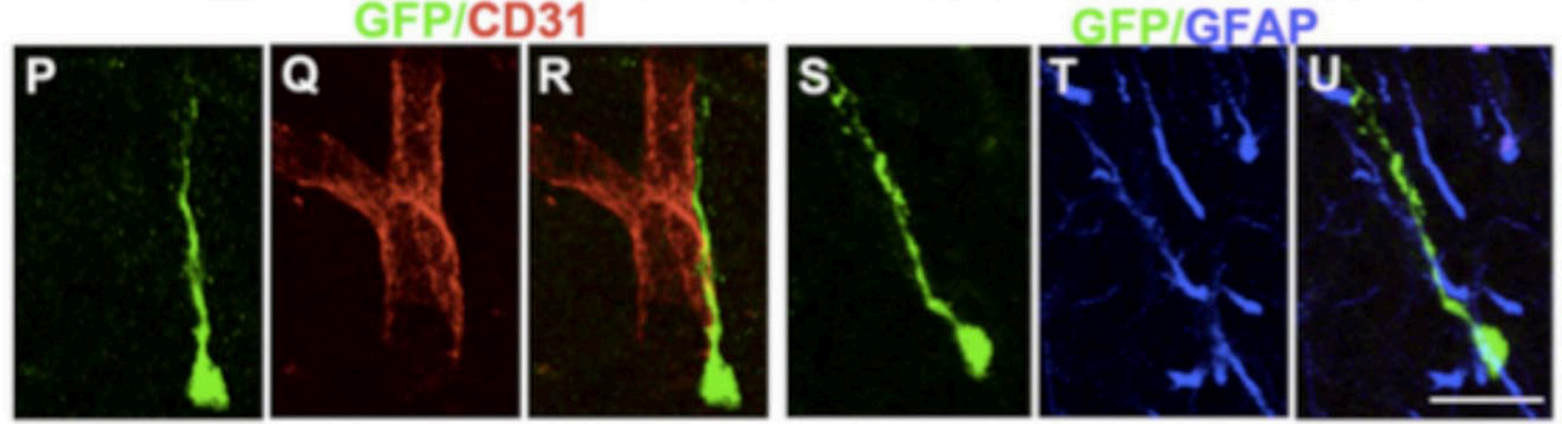

FIGURE 3 | Changes in cortical microenvironment assist progenitor migration after lesion. CD31 immunostaining of control intact cortex (A) and lesioned cortex at different times after injury (B-D). Double immunofluorescence confocal micrograph of Dcx (green) and CD31 (red) at day 7 (E-G) and day 15 (H). Similarly, double-immunostaining of astrocytes (blue) and neural progenitors (green) after 7 days of lesion (I,J). (K,L asterisk) Migration of progenitors (green) without any association. GFP immunostaining of brain sections 8 days after lentivirus injection (dpi) into the SVZ/RMS (M). In the cortex, GFP+ cells (green) co-express Dcx (red) (boxed in $\mathbf{N}$ ). GFP+ cells remain within the RMS in control brains (0). GFP+ progenitors also showed association with either blood vessels (P-R) or astrocytes (S-U) Scale bars: (A-D) $250 \mu \mathrm{m}, \mathbf{( E , H )} 50 \mu \mathrm{m}, \mathbf{( F , G )} 16 \mu \mathrm{m}, \mathbf{( I , J , P - U )} 20 \mu \mathrm{m}, \mathbf{( K , L )} 30 \mu \mathrm{m}, \mathbf{( N )} 80 \mu \mathrm{m},(\mathbf{N}$ inset) $40 \mu \mathrm{m}, \mathbf{( M , O )} 100 \mu \mathrm{m}$, (M inset) $50 \mu \mathrm{m}$ (Saha et al., 2013$)$. 
(Figures 3E-H) and GFAP + reactive astrocytes (Figures 3I-L), although a portion of neuroblasts was not associated with either of these cell types (Figures $\mathbf{3 M}-\mathbf{U}$ ), suggesting that multiple modes of migration may be present after injury (Saha et al., 2013).

Do human SVZ cells emigrate after injury? DCX+ cells in the SVZ decreased as patient age increased in children after TBI (Taylor et al., 2013). The density of immature migrating neuroblasts in infants (under 1 year of age) was significantly greater than in young (2-6 years of age) and older (7-10 years of age) children (Taylor et al., 2013). The DCX+ cells had migratory morphology and did not co-localize with markers for astrocytes, microglia, or macrophages in the periventricular white matter.

Quite a number of studies in the past decades suggest that SVZ cell emigration to TBI is guided by diffusible proteins (chemoattractants) secreted by cells in the injured region. In response to unilateral aspiration cortical lesion, Saha and colleagues demonstrated that SVZ neuroblast emigration toward injury is due to reactive astrocyte-derived SDF-1 signaling (Saha et al., 2013). SDF-1 is a key regulator of directed migration after injury as well as the homing of neural stem cells and increased mobility of neuroblasts (Kokovay et al., 2010; Moon et al., 2013). In a mouse model of TBI coupling stab wound and cryogenic injury, an SDF-1 analog increased the number of neuroblasts reaching the injury (Filippo et al., 2013). Moreover, the presence of analog increased SDF-1 expression, suggesting a positive feedback loop that maintains a chemoattractant gradient (Filippo et al., 2013). Similarly, the blockade of SDF-1/CXCR4 signaling after TBI using the CXCR4 antagonist AMD3100 led to fewer neuroblasts reaching the injury site. Finally, SDF-1 was also shown to increase phosphorylation of ERM (ezrin-radixinmoesin) proteins in migrating neuroblasts in response to TBI, helping to maintain the migratory morphology of these cells (Moon et al., 2013). Clearly, exogenous modulation of chemokine signaling may evolve into a key way to mobilize endogenous SVZ-mediated repair.

Most experiments studying SVZ cell migration after brain injury have utilized fluorescent cell labeling or tagged cells injected directly into the lateral ventricle or the SVZ. A library of retroviral vectors developed in the Cepko laboratory that was originally used in the SVZ to examine migration patterns and lineage relationships after cortical injury (Goings et al., 2004) has been recently used to show the early embryonic origin of SVZ stem cells (Fuentealba et al., 2015). Goings and colleagues showed that a portion of SVZ cells migrated toward the injury 4 days after aspiration cortical lesions and were still detected at 3 weeks after injury (Goings et al., 2004).

\section{TRAUMATIC BRAIN INJURY EFFECTS ON SVZ CELL SURVIVAL AND DIFFERENTIATION}

A growing body of evidence suggests that cells may survive better in the SVZ after TBI and mature for weeks after emigration to TBI (Table 1). The number of TUNEL+ SVZ cells was reduced 3 days post-controlled cortical impact injury in ephrinB3-/and EphB3 ${ }^{-/-}$mice (Theus et al., 2010). SVZ cell survival was also increased by administration of basic fibroblast growth factor (FGF2) but not epidermal growth factor (EGF) for 7 days following brain injury (Sun et al., 2009, 2010). FGF2 administration after fluid percussion injury in mouse increased newborn cell survival up to 4 weeks post injury, and the majority of survival was of neurons (Sun et al., 2009).

For regenerative value, not only do SVZ cells have to survive but they also have to differentiate appropriately after TBI. A recent study using tamoxifen-inducible Gli1-CreERT2;R26-YFP bi-transgenic mice demonstrated that the number of newborn SVZ cells increased post-controlled cortical impact brain injury, but few were found in the lesion area (Mierzwa et al., 2014). Six weeks post TBI, the number of YFP+/Dcx + double positive cells was still not significantly changed, yet there was a slight increase in the number of Dcx + cells observed in the dorsolateral SVZ (Mierzwa et al., 2014). In another study, neuroblasts migrating from the SVZ into the neocortex 2 weeks after cortical injury became proliferative $(\mathrm{BrdU}+/ \mathrm{Dcx}+)$, but very few new mature neurons were found adjacent to the lesion 28 days after the injury (Goodus et al., 2015). In piglets, injured at postnatal day 7 , cortical impact did not increase the total number of neuroblasts in white matter. However, 14 days post-injury, the number of Dcx + cells increased (Costine et al., 2015). Taken together, the data suggested that the stem cell niche (extrinsic factors) limits SVZ differentiation both before and after mechanical brain injuries.

Once the SVZ cells migrate out of the niche environment, they could also differentiate into astrocytes and oligodendrocytes, which are known to migrate into the forebrain in late brain development (Levison and Goldman, 1993). The retroviral lineage studies described above showed that SVZ cells that migrated to the corpus callosum after aspiration cortical lesions assumed oligodendrocytic morphology, whereas those that had moved near the cortical lesion became astrocytes (Goings et al., 2004). The predominant glial differentiation of SVZ cells also occurs in adult mouse brain after cortical contusion injury. BrdU+ cells homing to the ipsilateral cortex became either IBA$1+$ or GFAP+ cells, but not NeuN+ cells (Radomski et al., 2013). These data indicate that TBI induces progenitors to move out of the SVZ and become glia in rat (Chirumamilla et al., 2002) and mouse (Goings et al., 2004), although most reactive astrocytes in response to TBI are generated locally.

\section{MOLECULAR REGULATION OF SVZ CELLS AFTER TRAUMATIC BRAIN INJURY}

Since there does not seem to be significant SVZ-derived neuronal replacement after mechanical injuries, various molecular and cellular treatments have attempted to boost neurogenesis. Single or multiple doses of activated protein C injected intraperitoneally in mice promoted post-controlled cortical impact injury proliferation of neuroblasts in the SVZ and migration to the perilesional area (Petraglia et al., 2010). Granulocyte colony-stimulating factor (GCSF) delivered via osmotic pumps after fluid percussion injury in rats resulted in significantly increased Dcx + cell numbers in the ipsilateral 
SVZ (Yang et al., 2010). In another study, GCSF and/or human umbilical cord blood cell (hUBC) therapy was administered 1 week after controlled cortical impact (Acosta et al., 2014). Eight weeks later, the number of SVZ and hippocampal Dcx+ cells was significantly increased in all cohorts-hUCB, GCSF, and hUCB/GCSF. The therapeutic effect was also demonstrated via reduced hippocampal cell loss (Acosta et al., 2014). It is likely that during the next decade, significant improvements will be attained in exogenous stimulation of the SVZ's natural repair processes (Ihrie and Alvarez-Buylla, 2011).

A number of classic studies examined the effects of exogenous growth factors on SVZ neurogenesis, and they typically increased SVZ cell numbers in adjacent structures, suggesting induced emigration (Craig et al., 1996; Kuhn et al., 1997; Benraiss et al., 2001; Pencea et al., 2001a). BDNF or BDNF small molecule mimics caused SVZ cells to emigrate toward nearby nuclei (Benraiss et al., 2001; Pencea et al., 2001a; Fon et al., 2014) in a concentration-dependent manner (Petridis and El Maarouf, 2011). EGF and FGF2 injected into the lateral ventricles increased SVZ progenitor proliferation (Craig et al., 1996; Kuhn et al., 1997). EGF also caused SVZ cell emigration to the cerebral cortex, striatum, corpus callosum, and septum, and subsequent differentiation into astrocytes and oligodendrocytes (Craig et al., 1996; Gonzalez-Perez et al., 2009). In Craig et al. study, TGF$\alpha$ caused SVZ cell emigration into the striatum (Craig et al., 1996). Appearance of newborn cells could theoretically result from activation of latent neurogenic programs outside the SVZ (Palmer et al., 1999; Buffo et al., 2008; Amamoto and Arlotta, 2014), but it is unlikely that injection of growth factors alone could induce neurogenesis in the parenchyma (Grande et al., 2013).

In addition to the diffusible molecules described above, ECM and cell surface adhesion molecules regulate neural development. The SVZ expresses such molecules even after the rest of the brain has lost their expression postnatally (Miragall et al., 1990; Szele et al., 1994; Gates et al., 1995; Thomas et al., 1996). Many ECM molecules are made by astrocytes and regulate SVZ neuroblast motility (Husmann et al., 1992; Martoncikova et al., 2014; Giblin and Midwood, 2015). The ECM is enzymatically processed by matrix metalloproteinases (MMP) that are essential in regulating SVZ NSC quiescence, and identity and inhibition of MMPs limit neuroblast emigration from the SVZ to the striatum in stroke (Lee et al., 2006; Kang et al., 2008; Porlan et al., 2014). Although not an adhesion or ECM molecule, the cell transmembrane proteins EphrinB3-EphB3 control SVZ NSC proliferation via p53 in TBI in mouse (Theus et al., 2010). Taken together, the data suggest that regulation of the ECM and adhesive cell surface molecules in the SVZ is complicated, but important after TBI.

SVZ neural stem/progenitor cells are also regulated by intracellular transcriptional and epigenetic factors (Ihrie and Alvarez-Buylla, 2011). The transcription factor Gata3, for instance, can be induced in radial glial (NSC) of adult Zebrafish by stab wound lesions. Gata3 expression is FGF-dependent and is necessary for the reactive proliferation of radial glia and migration of newborn neurons in the regenerating telencephalon (Kizil et al., 2012). However, no evidence has shown the upregulation of Gata3 in the rodent SVZ after TBI (Yoshiya et al., 2003). In neuroblastoma, Gata3 is reported to activate Cyclin D1 and promote proliferation, whereas silencing of Gata3 induces differentiation (Molenaar et al., 2010; Peng et al., 2015). It could be worthwhile to examine whether exogenous activation of Gata3 in the rodent SVZ enhances the neurogenic ability of neural stem cells after mechanical injury. Compared to post-injury responses, far more transcriptional mechanisms have been reported in regulation of constitutive postnatal and adult SVZ neurogenesis (Hsieh, 2012; Urban and Guillemot, 2014).

It seems that exogenous manipulation of transcription factors may become crucial for brain repair, thereby considering the restriction of neuronal subtypes generated by neuroblasts that have migrated out of the SVZ/RMS/OB system (Teramoto et al., 2003; Liu et al., 2009; Young et al., 2011). For example, Fezf2 is required for layer 5 subcortical projection neuron development, and overexpression of Fezf2 in the postnatal SVZ is able to reprogram newborn cells from GABAergic interneurons into glutamatergic projection neurons (Kwan et al., 2012; Zuccotti et al., 2014). Moreover, recent studies have suggested that reactive astrocytes have stem cell potential after invasive brain injury (Buffo et al., 2008; Robel et al., 2011). Functional inactivation of Olig2 or overexpression of either Sox 2 or NeuroD1 in reactive astrocytes has successfully generated neurons in vivo (Buffo et al., 2005; Guo et al., 2013; Niu et al., 2013; Su et al., 2014). A systematic analysis of the roles of multiple transcription factors will facilitate the development of new brain repair therapies including in situ direct conversion of astrocytes (Arlotta et al., 2003; Amamoto and Arlotta, 2014).

In addition to transcription factors, a number of epigenetic regulators have been highlighted during SVZ neurogenesis (Hsieh, 2012; Urban and Guillemot, 2014). Chromatin modifiers, such as Ezh2, Jmjd3, Mll1, CHD7, and the BAF complex, contribute to proper neurogenesis and differentiation in the SVZ/RMS/OB (Lim et al., 2009; Feng et al., 2013; Ninkovic et al., 2013; Hwang et al., 2014; Park et al., 2014). Nevertheless, few of them have been studied in the SVZ response to mechanical brain injury. From the clinical perspective, activators and inhibitors of different epigenetic modification enzymes are commercially available. For example, the histone deacetylase inhibitor, sodium butyrate, is reported to elevate SVZ cell proliferation and enhance neurogenesis after stroke (Kim et al., 2009).

Grafting cells into cerebral cortex lesion cavities has indicated that cells can survive and develop new connections. Several papers have demonstrated that developing cells can be grafted into rodent TBIs (Castro et al., 1987, 1988; Girman and Golovina, 1988; Kolb et al., 1988; Sorensen et al., 1990). Engraftment of pluripotent stem cell-derived neural cells or even mesenchymal stem cells or bone marrow mononuclear cells into cortical lesions has also been studied in rodents (Gaillard et al., 2007; de Freitas et al., 2012; Espuny-Camacho et al., 2013; Tajiri et al., 2013; de Freitas et al., 2015; Michelsen et al., 2015). Overall these remarkable studies show that engrafted cells can survive, project axons into appropriate regions, and participate in at least some functional recovery. They also suggest that SVZ cells could be induced to perform similar feats of repair. 


\section{CONCLUSION}

The number of laboratories studying the potential regenerative abilities of rodent and human SVZ for cell replacement in mechanical injuries has significantly expanded in the last two decades. Most studies of lesions adjacent to or including the SVZ resulted in the alteration of SVZ biology with some combination of cell proliferation, migration, survival, or differentiation. These changes and differences can be explained by the level of severity, location, timing, or types of injury. Several different research groups using well-characterized injury models found similar or opposite features of SVZ cell property. Thus, generalization of SVZ response should be avoided, especially when comparing studies done in different species. To better understand the dynamics of SVZ cell plasticity, several researchers have analyzed intra- and extracellular mechanisms. Besides the well-recognized growth factors in SVZ biology including EGF and FGF2, TGFalpha and MMPs are involved in neuroblast emigration. In addition, the roles of several transcription factors (Gata3, Fezf2, Olig2) and epigenetic regulators (Ezh2, Jmjd3, Mll1, CHD7, BAF) in the SVZ govern SVZ cell proliferation and differentiation. Taken together, the field is now poised to translate some

\section{REFERENCES}

Acosta, S. A., Tajiri, N., Shinozuka, K., Ishikawa, H., Grimmig, B., Diamond, D. M., et al. (2013). Long-term upregulation of inflammation and suppression of cell proliferation in the brain of adult rats exposed to traumatic brain injury using the controlled cortical impact model. PLOS ONE 8:e53376. doi: 10.1371/journal.pone.0053376

Acosta, S. A., Tajiri, N., Shinozuka, K., Ishikawa, H., Sanberg, P. R., SanchezRamos, J., et al. (2014). Combination therapy of human umbilical cord blood cells and granulocyte colony stimulating factor reduces histopathological and motor impairments in an experimental model of chronic traumatic brain injury. PLoS ONE 9:e90953. doi: 10.1371/journal.pone.0090953

Agrawal, A., Timothy, J., Pandit, L., Manju, M. (2006) Post-traumatic epilepsy: an overview. Clin. Neurol. Neurosurg. 108, 433-439.

Alonso, G., Prieto, M., and Chauvet, N. (1999). Tangential migration of young neurons arising from the subventricular zone of adult rats is impaired by surgical lesions passing through their natural migratory pathway. J. Comp. Neurol. 405, 508-528.

Amamoto, R., and Arlotta, P. (2014). Development-inspired reprogramming of the mammalian central nervous system. Science 343:1239882. doi: $10.1126 /$ science. 1239882

Arlotta, P., Magavi, S. S., and Macklis, J. D. (2003). Induction of adult neurogenesis: molecular manipulation of neural precursors in situ. Ann. N.Y. Acad. Sci. 991, 229-236. doi: 10.1111/j.1749-6632.2003.tb07479.x

Azim, K., Fischer, B., Hurtado-Chong, A., Draganova, K., Cantu, C., Zemke, M., et al. (2014b). Persistent Wnt/beta-catenin signaling determines dorsalization of the postnatal subventricular zone and neural stem cell specification into oligodendrocytes and glutamatergic neurons. Stem Cells 32, 1301-1312. doi: 10.1002/stem.1639

Azim, K., Rivera, A., Raineteau, O., and Butt, A. M. (2014a). GSK3beta regulates oligodendrogenesis in the dorsal microdomain of the subventricular zone via Wnt-beta-catenin signaling. Glia 62, 778-779. doi: 10.1002/glia.22641

Bedard, A., Cossette, M., Levesque, M., and Parent, A. (2002). Proliferating cells can differentiate into neurons in the striatum of normal adult monkey. Neurosci. Lett. 328, 213-216. doi: 10.1016/S0304-3940(02)00530-X

Benraiss, A., Chmielnicki, E., Lerner, K., Roh, D., and Goldman, S. A. (2001). Adenoviral brain-derived neurotrophic factor induces both neostriatal and of the fundamental findings into clinically relevant treatment modalities designed to augment SVZ neurogenesis, emigration, and neural repair.

\section{AUTHOR CONTRIBUTIONS}

EC wrote review, composed figures and table. IA wrote review, composed figures. MM wrote review, composed figures. BS wrote review. MD wrote review. FS wrote review.

\section{FUNDING}

MD supported by NIH RO1 NIH/NINDS R01NS086945-01. FS supported by MRC/NNSFC project grant MR/M010554/1. BS supported by China Scholarship Council and Henry Lester Trust. MM support by FAPESP 2012/06810-1 and 2014/00927-0.

\section{ACKNOWLEDGMENTS}

This work was funded by the MRC. We would like to thank members of the Szele Laboratory for helpful comments on the manuscript. olfactory neuronal recruitment from endogenous progenitor cells in the adult forebrain. J. Neurosci. 21, 6718-6731.

Bergmann, O., Liebl, J., Bernard, S., Alkass, K., Yeung, M. S., Steier, P., et al. (2012). The age of olfactory bulb neurons in humans. Neuron 74, 634-639. doi: 10.1016/j.neuron.2012.03.030

Bernier, P. J., Vinet, J., Cossette, M., and Parent, A. (2000). Characterization of the subventricular zone of the adult human brain: evidence for the involvement of Bcl-2. Neurosci. Res. 37, 67-78. doi: 10.1016/S0168-0102(00)00102-4

Bramlett, H. M., and Dietrich, W. D. (2002). Quantitative structural changes in white and gray matter 1 year following traumatic brain injury in rats. Acta Neuropathol. (Berl.) 103, 607-614. doi: 10.1007/s00401-001-0510-8

Bruni, J. E., Del Bigio, M. R., and Clattenburg, R. E. (1985). Ependyma: normal and pathological. A review of the literature. Brain Res. 356, 1-19. doi: 10.1016/01650173(85)90016-5

Brus, M., Meurisse, M., Gheusi, G., Keller, M., Lledo, P., and Levy, F. (2012). Dynamics of olfactory and hippocampal neurogenesis in adult sheep. J. Comp. Neurol. 521, 169-188. doi: 10.1002/cne.23169

Buffo, A., Rite, I., Tripathi, P., Lepier, A., Colak, D., Horn, A. P., et al. (2008). Origin and progeny of reactive gliosis: a source of multipotent cells in the injured brain. Proc. Natl. Acad. Sci. U.S.A. 105, 3581-3586. doi: 10.1073/pnas.0709002105

Buffo, A., Vosko, M. R., Erturk, D., Hamann, G. F., Jucker, M., Rowitch, D., et al. (2005). Expression pattern of the transcription factor Olig2 in response to brain injuries: implications for neuronal repair. Proc. Natl. Acad. Sci. U.S.A. 102, 18183-18188. doi: 10.1073/pnas.0506535102

Bye, N., Carron, S., Han, X., Agyapomaa, D., Ng, S. Y., Yan, E., et al. (2011). Neurogenesis and glial proliferation are stimulated following diffuse traumatic brain injury in adult rats. J. Neurosci. Res. 89, 986-1000. doi: 10.1002/jnr.22635

Carbonell, W. S., Maris, D. O., McCall, T., and Grady, M. S. (1998). Adaptation of the fluid percussion injury model to the mouse. J. Neurotrauma 15, 217-229. doi: $10.1089 /$ neu.1998.15.217

Castro, A. J., Tonder, N., Sunde, N. A., and Zimmer, J. (1987). Fetal cortical transplants in the cerebral hemisphere of newborn rats: a retrograde fluorescent analysis of connections. Exp. Brain Res. 66, 533-542. doi: 10.1007/BF00270686

Castro, A. J., Tonder, N., Sunde, N. A., and Zimmer, J. (1988). Fetal neocortical transplants grafted to the cerebral cortex of newborn rats receive afferents from the basal forebrain, locus coeruleus and midline raphe. Exp. Brain Res. 69, 613-622. doi: $10.1007 / \mathrm{BF} 00247313$ 
Chen, S., Pickard, J. D., and Harris, N. G. (2003). Time course of cellular pathology after controlled cortical impact injury. Exp. Neurol. 182, 87-102. doi: 10.1016/S0014-4886(03)00002-5

Chen, X. H., Iwata, A., Nonaka, M., Browne, K. D., and Smith, D. H. (2003). Neurogenesis and glial proliferation persist for at least one year in the subventricular zone following brain trauma in rats. J. Neurotrauma 20, 623-631. doi: 10.1089/089771503322144545

Chenn, A., and Walsh, C. A. (2002). Regulation of cerebral cortical size by control of cell cycle exit in neural precursors. Science 297, 365-369. doi: 10.1126/science.1074192

Chirumamilla, S., Sun, D., Bullock, M. R., and Colello, R. J. (2002). Traumatic brain injury induced cell proliferation in the adult mammalian central nervous system. J. Neurotrauma 19, 693-703. doi: 10.1089/08977150260139084

Coronado, V. G., Xu, L., Basavaraju, S. V., McGuire, L. C., Wald, M. M., Faul, M. D., et al. (2011). Surveillance for traumatic brain injury-related deaths-United States, 1997-2007. MMWR. Surveill. Summ. 60, 1-32.

Costine, B. A., Missios, S., Taylor, S. R., McGuone, D., Smith, C. M., Dodge, C. P., et al. (2015). The subventricular zone in the immature piglet brain: anatomy and exodus of neuroblasts into white matter after traumatic brain injury. Dev. Neurosci. 37, 115-130. doi: 10.1159/000369091

Craig, C. G., Tropepe, V., Morshead, C. M., Reynolds, B. A., Weiss, S., and van der Kooy, D. (1996). In vivo growth factor expansion of endogenous subependymal neural precursor cell populations in the adult mouse brain. J. Neurosci. 16, 2649-2658.

Curtis, M. A., Kam, M., Nannmark, U., Anderson, M. F., Axell, M. Z., Wikkelso, C., et al. (2007). Human neuroblasts migrate to the olfactory bulb via a lateral ventricular extension. Science 315, 1243-1249. doi: 10.1126/science.1136281

de Freitas, H. T., da Silva, V. G., and Giraldi-Guimaraes, A. (2012). Comparative study between bone marrow mononuclear fraction and mesenchymal stem cells treatment in sensorimotor recovery after focal cortical ablation in rats. Behav. Brain Funct. 8:58. doi: 10.1186/1744-9081-8-58

de Freitas, H. T., Rebel, M. G., Coelho, B. P., da Silva, V. G., Galaxe-Almeida, G. G., and Giraldi-Guimaraes, A. (2015). Effect of the treatment of focal brain ablation in rat with bone marrow mesenchymal stromal cells on sensorimotor recovery and cytokine production. J. Neurol. Sci. 348, 166-173. doi: 10.1016/j.jns.2014.11.032

Di Curzio, D. L., Buist, R. J., and Del Bigio, M. R. (2013). Reduced subventricular zone proliferation and white matter damage in juvenile ferrets with kaolin-induced hydrocephalus. Exp. Neurol. 248, 112-128. doi: 10.1016/j.expneurol.2013.06.004

Dizon, M. L. V., and Szele, F. G. (2005). “The subventricular zone responds dynamically to mechanical brain injuries," in Mammalian Subventricular Zones: Their Roles in Brain Development, Cell Replacement, And Disease, ed S. W. Levison (New York, NY: Kluwer Academic/Plenum Publishers), 210-241.

Eriksson, P. S., Perfilieva, E., Bjork-Eriksson, T., Alborn, A. M., Nordborg, C., Peterson, D. A., et al. (1998). Neurogenesis in the adult human hippocampus. Nat. Med. 4, 1313-1317. doi: 10.1038/3305

Ernst, A., Alkass, K., Bernard, S., Salehpour, M., Perl, S., Tisdale, J., et al. (2014). Neurogenesis in the striatum of the adult human brain. Cell 156, 1072-1083. doi: 10.1016/j.cell.2014.01.044

Espuny-Camacho, I., Michelsen, K. A., Gall, D., Linaro, D., Hasche, A., Bonnefont, J., et al. (2013). Pyramidal neurons derived from human pluripotent stem cells integrate efficiently into mouse brain circuits in vivo. Neuron $77,440-456$. doi: 10.1016/j.neuron.2012.12.011

Farge, E. (2003). Mechanical induction of twist in the Drosophila foregut/stomodeal primordium. Curr. Biol. 13, 1365-1377. doi: 10.1016/S0960-9822(03)00576-1

Feng, W., Khan, M. A., Bellvis, P., Zhu, Z., Bernhardt, O., Herold-Mende, C., et al. (2013). The Chromatin Remodeler CHD7 regulates adult neurogenesis via activation of SoxC transcription factors. Cell Stem Cell 13, 62-72. doi: 10.1016/j.stem.2013.05.002

Filippo, T. R., Galindo, L. T., Barnabe, G. F., Ariza, C. B., Mello, L. E., Juliano, M. A., et al. (2013). CXCL12 N-terminal end is sufficient to induce chemotaxis and proliferation of neural stem/progenitor cells. Stem Cell Res. 11, 913-925. doi: 10.1016/j.scr.2013.06.003

Fon, D., Zhou, K., Ercole, F., Fehr, F., Marchesan, S., Minter, M. R., et al. (2014). Nanofibrous scaffolds releasing a small molecule BDNF-mimetic for the re-direction of endogenous neuroblast migration in the brain. Biomaterials 35, 2692-2712. doi: 10.1016/j.biomaterials.2013.12.016

Fuentealba, L. C., Rompani, S. B., Parraguez, J. I., Obernier, K., Romero, R., Cepko, C. L., et al. (2015). Embryonic origin of postnatal neural stem cells. Cell 161, 1644-1655. doi: 10.1016/j.cell.2015.05.041

Gaillard, A., Prestoz, L., Dumartin, B., Cantereau, A., Morel, F., Roger, M., et al. (2007). Reestablishment of damaged adult motor pathways by grafted embryonic cortical neurons. Nat. Neurosci. 10, 1294-1299. doi: 10.1038/nn1970

Gates, M. A., Thomas, L. B., Howard, E. M., Laywell, E. D., Sajin, B., Faissner, A. et al. (1995). Cell and molecular analysis of the developing and adult mouse subventricular zone of the cerebral hemispheres. J. Comp. Neurol. 361, 249-266. doi: 10.1002/cne.903610205

Giblin, S. P., and Midwood, K. S. (2015). Tenascin-C: form versus function. Cell Adh. Migr. 9, 48-82. doi: 10.4161/19336918.2014.987587

Gil-Perotin, S., Duran-Moreno, M., Belzunegui, S., Luquin, M. R., and GarciaVerdugo, J. M. (2009). Ultrastructure of the subventricular zone in Macaca fascicularis and evidence of a mouse-like migratory stream. J. Comp. Neurol. 514, 533-554. doi: 10.1002/cne.22026

Gil-Perotin, S., Duran-Moreno, M., Cebrian-Silla, A., Ramirez, M., Garcia-Belda, P., and Garcia-Verdugo, J. M. (2013). Adult neural stem cells from the subventricular zone: a review of the neurosphere assay. Anat. Rec. (Hoboken). 296, 1435-1452. doi: 10.1002/ar.22746

Girman, S. V., and Golovina, I. L. (1988). Electrophysiologic research on the afferent connections of embryonic neocortex allografts inserted into the projection zones of the cortex in adult rats. Neirofiziologiia 20, 448-456.

Givogri, M. I., de Planell, M., Galbiati, F., Superchi, D., Gritti, A., Vescovi, A., et al. (2006). Notch signaling in astrocytes and neuroblasts of the adult subventricular zone in health and after cortical injury. Dev. Neurosci. 28, 81-91. doi: 10.1159/000090755

Goings, G. E., Kozlowski, D. A., and Szele, F. G. (2006). Differential activation of microglia in neurogenic versus non-neurogenic regions of the forebrain. Glia 54, 329-342. doi: 10.1002/glia.20381

Goings, G. E., Sahni, V., and Szele, F. G. (2004). Migration patterns of subventricular zone cells in adult mice change after cerebral cortex injury. Brain Res. 996, 213-226. doi: 10.1016/j.brainres.2003.10.034

Goings, G., Wibisono, B., and Szele, F. (2002). Cerebral cortex lesions decrease the number of bromodeoxyuridine-positive subventricular zone cells in mice. Neurosci. Lett. 329, 161-164. doi: 10.1016/S0304-3940(02)00611-0

Gonzalez-Perez, O., Romero-Rodriguez, R., Soriano-Navarro, M., GarciaVerdugo, J. M., and Alvarez-Buylla, A. (2009). Epidermal growth factor induces the progeny of subventricular zone type B cells to migrate and differentiate into oligodendrocytes. Stem Cells 27, 2032-2043. doi: 10.1002/stem.119

Goodus, M. T., Guzman, A. M., Calderon, F., Jiang, Y., and Levison, S. W. (2015). Neural stem cells in the immature, but not the mature, subventricular zone respond robustly to traumatic brain injury. Dev. Neurosci. 37, 29-42. doi: $10.1159 / 000367784$

Gotts, J. E., and Chesselet, M. F. (2005). Mechanisms of subventricular zone expansion after focal cortical ischemic injury. J. Comp. Neurol. 488, 201-214. doi: 10.1002/cne.20609

Grande, A., Sumiyoshi, K., Lopez-Juarez, A., Howard, J., Sakthivel, B., Aronow, B., et al. (2013). Environmental impact on direct neuronal reprogramming in vivo in the adult brain. Nat. Commun. 4, 2373. doi: 10.1038/ncomms3373

Grodzinsky, A. J., Levenston, M. E., Jin, M., and Frank, E. H. (2000). Cartilage tissue remodeling in response to mechanical forces. Annu. Rev. Biomed. Eng. 2, 691-713. doi: 10.1146/annurev.bioeng.2.1.691

Guirao, B., Meunier, A., Mortaud, S., Aguilar, A., Corsi, J. M., Strehl, L., et al. (2010). Coupling between hydrodynamic forces and planar cell polarity orients mammalian motile cilia. Nat. Cell Biol. 12, 341-350. doi: 10.1038/ncb2040

Guo, Z., Zhang, L., Wu, Z., Chen, Y., Wang, F., and Chen, G. (2013). In vivo direct reprogramming of reactive glial cells into functional neurons after brain injury and in an Alzheimers Disease Model. Cell Stem Cell. 14, 188-202. doi: 10.1016/j.stem.2013.12.001

Hart, T., Brenner, L., Clark, A. N., Bogner, J. A., Novack, T. A., Chervoneva, I., et al. (2011). Major and minor depression after traumatic brain injury. Arch. Phys. Med. Rehabil. 92, 1211-1219.

Holmin, S., Almqvist, P., Lendahl, U., and Mathiesen, T. (1997). Adult nestinexpressing subependymal cells differentiate to astrocytes in response to 
brain injury. Eur. J. Neurosci. 9, 65-75. doi: 10.1111/j.1460-9568.1997. tb01354.x

Hsieh, J. (2012). Orchestrating transcriptional control of adult neurogenesis. Genes Dev. 26, 1010-1021. doi: 10.1101/gad.187336.112

Husmann, K., Faissner, A., and Schachner, M. (1992). Tenascin promotes cerebellar granule cell migration and neurite outgrowth by different domains in the fibronectin type III repeats. J. Cell Biol. 116, 1475-1486. doi: 10.1083/jcb.116.6.1475

Hwang, W. W., Salinas, R. D., Siu, J. J., Kelley, K. W., Delgado, R. N., Paredes, M. F., et al. (2014). Distinct and separable roles for EZH2 in neurogenic astroglia. Elife 3:e02439. doi: 10.7554/elife.02439

Ihrie, R. A., and Alvarez-Buylla, A. (2011). Lake-front property: a unique germinal niche by the lateral ventricles of the adult brain. Neuron 70, 674-686. doi: 10.1016/j.neuron.2011.05.004

Ingber, D. E. (1997). Tensegrity: the architectural basis of cellular mechanotransduction. Annu. Rev. Physiol. 59, 575-599. doi: 10.1146/annurev. physiol.59.1.575

Ingber, D. E. (2002). Mechanical signaling and the cellular response to extracellular matrix in angiogenesis and cardiovascular physiology. Circ. Res. 91, 877-887. doi: 10.1161/01.RES.0000039537.73816.E5

Iwamoto, Y., Yamaki, T., Murakami, N., Umeda, M., Tanaka, C., Higuchi, T., et al. (1997). Investigation of morphological change of lateral and midline fluid percussion injury in rats, using magnetic resonance imaging. Neurosurgery 40, $163-167$.

Jacques, T. S., Relvas, J. B., Nishimura, S., Pytela, R., Edwards, G. M., Streuli, C. H., et al. (1998). Neural precursor cell chain migration and division are regulated through different betal integrins. Development 125, 3167-3177.

Jankovski, A., Garcia, C., Soriano, E., and Sotelo, C. (1998). Proliferation, migration and differentiation of neuronal progenitor cells in the adult mouse subventricular zone surgically separated from its olfactory bulb. Eur. J. Neurosci. 10, 3853-3868. doi: 10.1046/j.1460-9568.1998.00397.x

Jankovski, A., and Sotelo, C. (1996). Subventricular zone-olfactory bulb migratory pathway in the adult mouse: cellular composition and specificity as determined by heterochronic and heterotopic transplantation. J. Comp. Neurol. 371, 376-396.

Kam, M., Curtis, M. A., McGlashan, S. R., Connor, B., Nannmark, U., and Faull, R. L. (2009). The cellular composition and morphological organization of the rostral migratory stream in the adult human brain. J. Chem. Neuroanat. 37, 196-205. doi: 10.1016/j.jchemneu.2008.12.009

Kang, S. S., Kook, J. H., Hwang, S., Park, S. H., Nam, S. C., and Kim, J. K. (2008). Inhibition of matrix metalloproteinase- 9 attenuated neural progenitor cell migration after photothrombotic ischemia. Brain Res. 1228, 20-26. doi: 10.1016/j.brainres.2008.06.056

Keller, R., Davidson, L. A., and Shook, D. R. (2003). How we are shaped: the biomechanics of gastrulation. Differentiation 71, 171-205. doi: 10.1046/j.14320436.2003.710301.x

Kim, H. J., Leeds, P., and Chuang, D. M. (2009). The HDAC inhibitor, sodium butyrate, stimulates neurogenesis in the ischemic brain. J. Neurochem. 110, 1226-1240. doi: 10.1111/j.1471-4159.2009.06212.x

Kirschenbaum, B., Doetsch, F., Lois, C., and Alvarez-Buylla, A. (1999). Adult subventricular zone neuronal precursors continue to proliferate and migrate in the absence of the olfactory bulb. J. Neurosci. 19, 2171-2180.

Kizil, C., Kyritsis, N., Dudczig, S., Kroehne, V., Freudenreich, D., Kaslin, J., et al. (2012). Regenerative neurogenesis from neural progenitor cells requires injury-induced expression of gata3. Dev. Cell 23, 1230-1237. doi: 10.1016/j.devcel.2012.10.014

Kochanek, P. M., Jackson, T. C., Ferguson, N. M., Carlson, S. W., Simon, D. W., Brockman, E. C., et al. (2015). Emerging therapies in traumatic brain injury. Semin. Neurol. 35, 83-100. doi: 10.1055/s-0035-1544237

Kokovay, E., Goderie, S., Wang, Y., Lotz, S., Lin, G., Sun, Y., et al. (2010). Adult SVZ lineage cells home to and leave the vascular niche via differential responses to SDF1/CXCR4 signaling. Cell Stem Cell 7, 163-173. doi: 10.1016/j.stem.2010.05.019

Kolb, B., Reynolds, B., and Fantie, B. (1988). Frontal cortex grafts have opposite effects at different postoperative recovery times. Behav. Neural Biol. 50, 193-206. doi: 10.1016/S0163-1047(88) 90881-3
Kornack, D. R., and Rakic, P. (2001a). The generation, migration, and differentiation of olfactory neurons in the adult primate brain. Proc. Natl. Acad. Sci. U.S.A. 98, 4752-4757. doi: 10.1073/pnas.081074998

Kornack, D. R., and Rakic, P. (2001b). Cell proliferation without neurogenesis in adult primate neocortex. Science 294, 2127-2130. doi: 10.1126/science.1065467

Kuhn, H. G., Winkler, J., Kempermann, G., Thal, L. J., and Gage, F. H. (1997). Epidermal growth factor and fibroblast growth factor-2 have different effects on neural progenitors in the adult rat brain. J. Neurosci. 17, 5820-5829.

Kukekov, V. G., Laywell, E. D., Suslov, O., Davies, K., Scheffler, B., Thomas, L. B., et al. (1999). Multipotent stem/progenitor cells with similar properties arise from two neurogenic regions of adult human brain. Exp. Neurol. 156, 333-344. doi: 10.1006/exnr.1999.7028

Kwan, K. Y., Sestan, N., and Anton, E. S. (2012). Transcriptional co-regulation of neuronal migration and laminar identity in the neocortex. Development 139, 1535-1546. doi: 10.1242/dev.069963

Lee, S. R., Kim, H. Y., Rogowska, J., Zhao, B. Q., Bhide, P., Parent, J. M., et al. (2006). Involvement of matrix metalloproteinase in neuroblast cell migration from the subventricular zone after stroke. J. Neurosci. 26, 3491-3495. doi: 10.1523/JNEUROSCI.4085-05.2006

Levison, S. W., and Goldman, J. E. (1993). Both oligodendrocytes and astrocytes develop from progenitors in the subventricular zone of postnatal rat forebrain. Neuron 10, 201-212. doi: 10.1016/0896-6273(93)90311-E

Li, Y., Wu, D., Wu, C., Qu, Z., Zhao, Y., Li, W., et al. (2014). Changes in neural stem cells in the subventricular zone in a rat model of communicating hydrocephalus. Neurosci. Lett. 578, 153-158. doi: 10.1016/j.neulet.2014.06.053

Liard, O., Segura, S., Pascual, A., Gaudreau, P., Fusai, T., and Moyse, E. (2009). In vitro isolation of neural precursor cells from the adult pig subventricular zone. J. Neurosci. Methods 182, 172-179. doi: 10.1016/j.jneumeth.2009.06.008

Lim, D. A., Huang, Y. C., Swigut, T., Mirick, A. L., Garcia-Verdugo, J. M., Wysocka, J., et al. (2009). Chromatin remodelling factor Mll1 is essential for neurogenesis from postnatal neural stem cells. Nature 458, 529-533. doi: 10.1038 /nature 07726

Liu, F., You, Y., Li, X., Ma, T., Nie, Y., Wei, B., et al. (2009). Brain injury does not alter the intrinsic differentiation potential of adult neuroblasts. J. Neurosci. 29, 5075-5087. doi: 10.1523/JNEUROSCI.0201-09.2009

Liu, G., and Rao, Y. (2003). Neuronal migration from the forebrain to the olfactory bulb requires a new attractant persistent in the olfactory bulb. J. Neurosci. 23, 6651-6659.

Lois, C., and Alvarez-Buylla, A. (1993). Proliferating subventricular zone cells in the adult mammalian forebrain can differentiate into neurons and glia. Proc. Natl. Acad. Sci. U.S.A. 90, 2074-2077. doi: 10.1073/pnas.90.5.2074

Lois, C., Garcia-Verdugo, J. M., and Alvarez-Buylla, A. (1996). Chain migration of neuronal precursors. Science 271, 978-981. doi: 10.1126/science.271.5251.978

Low, V. F., Faull, R. L., Bennet, L., Gunn, A. J., and Curtis, M. A. (2013). Neurogenesis and progenitor cell distribution in the subgranular zone and subventricular zone of the adult sheep brain. Neuroscience 244, 173-187. doi: 10.1016/j.neuroscience.2013.04.006

Lowenstein, D. H. (2009) Epilepsy after head injury: an overview. Epilepsia 50(Suppl. 2), 4-9.

Luzzati, F., De Marchis, S., Fasolo, A., and Peretto, P. (2006). Neurogenesis in the caudate nucleus of the adult rabbit. J. Neurosci. 26, 609-621. doi: 10.1523/JNEUROSCI.4371-05.2006

Margulies, S., Hicks, R., and Combination Therapies for Traumatic Brain Injury Workshop Leaders. (2009). Combination therapies for traumatic brain injury: prospective considerations. J. Neurotrauma 26, 925-939. doi: 10.1089/neu.2008.0794

Marklund, N., Bakshi, A., Castelbuono, D. J., Conte, V., and McIntosh, T. K. (2006). Evaluation of pharmacological treatment strategies in traumatic brain injury. Curr. Pharm. Des. 12, 1645-1680. doi: 10.2174/138161206776843340

Martoncikova, M., Fabianova, K., Schreiberova, A., Blasko, J., Almasiova, V., and Racekova, E. (2014). Astrocytic and vascular scaffolding for neuroblast migration in the rostral migratory stream. Curr. Neurovasc. Res. 11, 321-329. doi: 10.2174/1567202611666140903121253

McIntosh, T. K., Noble, L., Andrews, B., and Faden, A. I. (1987). Traumatic brain injury in the rat: characterization of a midline fluid-percussion model. Cent. Nerv. Syst. Trauma 4, 119-134. doi: 10.1089/cns.1987.4.119 
Mercier, F., Kitasako, J. T., and Hatton, G. I. (2002). Anatomy of the brain neurogenic zones revisited: fractones and the fibroblast/macrophage network. J. Comp. Neurol. 451, 170-188. doi: 10.1002/cne.10342

Michelsen, K. A., Acosta-Verdugo, S., Benoit-Marand, M., Espuny-Camacho, I., Gaspard, N., Saha, B., et al. (2015). Area-specific reestablishment of damaged circuits in the adult cerebral cortex by cortical neurons derived from mouse embryonic stem cells. Neuron 85, 982-997. doi: 10.1016/j.neuron.2015.02.001

Mierzwa, A. J., Sullivan, G. M., Beer, L. A., Ahn, S., and Armstrong, R. C. (2014). Comparison of cortical and white matter traumatic brain injury models reveals differential effects in the subventricular zone and divergent Sonic hedgehog signaling pathways in neuroblasts and oligodendrocyte progenitors. ASN Neuro 6:1759091414551782. doi: 10.1177/1759091414551782

Miragall, F., Kadmon, G., Faissner, A., Antonicek, H., and Schachner, M. (1990). Retention of J1/tenascin and the polysialylated form of the neural cell adhesion molecule (N-CAM) in the adult olfactory bulb. J. Neurocytol. 19, 899-914. doi: 10.1007/BF01186818

Mitro, A., and Palkovits, M. (1981). Morphology of the rat brain ventricles, ependyma, and periventricular structures. Bibl. Anat. 21, 1-110.

Molenaar, J. J., Ebus, M. E., Koster, J., Santo, E., Geerts, D., Versteeg, R., et al. (2010). Cyclin D1 is a direct transcriptional target of GATA3 in neuroblastoma tumor cells. Oncogene 29, 2739-2745. doi: 10.1038/onc.2010.21

Moon, Y., Kim, J. Y., Kim, W. R., Kim, H. J., Jang, M. J., Nam, Y., et al. (2013). Function of ezrin-radixin-moesin proteins in migration of subventricular zonederived neuroblasts following traumatic brain injury. Stem Cells 31, 1696-1705. doi: 10.1002/stem.1420

Ng, K. L., Li, J. D., Cheng, M. Y., Leslie, F. M., Lee, A. G., and Zhou, Q. Y. (2005). Dependence of olfactory bulb neurogenesis on prokineticin 2 signaling. Science 308, 1923-1927. doi: 10.1126/science.1112103

Ninkovic, J., Steiner-Mezzadri, A., Jawerka, M., Akinci, U., Masserdotti, G., Petricca, S., et al. (2013). The BAF complex interacts with Pax6 in adult neural progenitors to establish a neurogenic cross-regulatory transcriptional network. Cell Stem Cell. 13, 403-418. doi: 10.1016/j.stem.2013.07.002

Niu, W., Zang, T., Zou, Y., Fang, S., Smith, D. K., Bachoo, R., et al. (2013). In vivo reprogramming of astrocytes to neuroblasts in the adult brain. Nat. Cell Biol. 15, 1164-1175. doi: 10.1038/ncb2843

Ostenfeld, T., Tai, Y. T., Martin, P., Deglon, N., Aebischer, P., and Svendsen, C. N. (2002). Neurospheres modified to produce glial cell line-derived neurotrophic factor increase the survival of transplanted dopamine neurons. J. Neurosci. Res. 69, 955-965. doi: 10.1002/jnr.10396

Palmer, T. D., Markakis, E. A., Willhoite, A. R., Safar, F., and Gage, F. H. (1999). Fibroblast growth factor-2 activates a latent neurogenic program in neural stem cells from diverse regions of the adult CNS. J. Neurosci. 19, 8487-8497.

Park, D. H., Hong, S. J., Salinas, R. D., Liu, S. J., Sun, S. W., Sgualdino, J., et al. (2014). Activation of neuronal gene expression by the JMJD3 demethylase is required for postnatal and adult brain neurogenesis. Cell Rep. 8, 1290-1299. doi: 10.1016/j.celrep.2014.07.060

Pencea, V., Bingaman, K. D., Freedman, L. J., and Luskin, M. B. (2001b). Neurogenesis in the subventricular zone and rostral migratory stream of the neonatal and adult primate forebrain. Exp. Neurol. 172, 1-16. doi: 10.1006/exnr.2001.7768

Pencea, V., Bingaman, K. D., Wiegand, S. J., and Luskin, M. B. (2001a). Infusion of brain-derived neurotrophic factor into the lateral ventricle of the adult rat leads to new neurons in the parenchyma of the striatum, septum, thalamus, and hypothalamus. J. Neurosci. 21, 6706-6717.

Peng, H. W., Ke, X. X., Hu, R. J., Yang, L. Q., Cui, H. J., and Wei, Y. Q. (2015). Essential role of GATA3 in regulation of differentiation and cell proliferation in SK-N-SH neuroblastoma cells. Mol. Med. Rep. 11, 881-886. doi: 10.3892/mmr.2014.2809

Petraglia, A. L., Marky, A. H., Walker, C., Thiyagarajan, M., and Zlokovic, B. V. (2010). Activated protein $C$ is neuroprotective and mediates new blood vessel formation and neurogenesis after controlled cortical impact. Neurosurgery 66, 165-171. discussion: 171-162. doi: 10.1227/01.neu.0000363148.49779.68

Petridis, A. K., and El Maarouf, A. (2011). Brain-derived neurotrophic factor levels influence the balance of migration and differentiation of subventricular zone cells, but not guidance to the olfactory bulb. J. Clin. Neurosci. 18, 265-270. doi: 10.1016/j.jocn.2010.06.021

Porlan, E., Marti-Prado, B., Morante-Redolat, J. M., Consiglio, A., Delgado, A. C., Kypta, R., et al. (2014). MT5-MMP regulates adult neural stem cell functional quiescence through the cleavage of N-cadherin. Nat. Cell Biol. 16, 629-638. doi: $10.1038 /$ ncb2993

Prins, M. L., and Hovda, D. A. (2003). Developing experimental models to address traumatic brain injury in children. J. Neurotrauma 20, 123-137. doi: 10.1089/08977150360547053

Radomski, K. L., Zhou, Q., Yi, K. J., and Doughty, M. L. (2013). Cortical contusion injury disrupts olfactory bulb neurogenesis in adult mice. BMC Neurosci. 14:142. doi: 10.1186/1471-2202-14-142

Ramaswamy, S., Goings, G. E., Soderstrom, K. E., Szele, F. G., and Kozlowski, D. A. (2005). Cellular proliferation and migration following a controlled cortical impact in the mouse. Brain Res. 1053, 38-53. doi: 10.1016/j.brainres.2005.06.042

Reider, G. II, Groswasser, Z., Ommaya, A. K., Schwab, K., Pridgen, A., Brown, H. R., et al. (2002). Quantitive imaging in late traumatic brain injury. Part I: late imaging parameters in closed and penetrating head injuries. Brain Inj. 16, 517-525. doi: 10.1080/02699050110119141

Robel, S., Berninger, B., and Gotz, M. (2011). The stem cell potential of glia: lessons from reactive gliosis. Nat. Rev. Neurosci. 12, 88-104. doi: 10.1038/nrn2978

Rosenthal, M., Christensen, B. K., Ross, T. P. (1998) Depression following traumatic brain injury. Arch. Phys. Med. Rehabil. 79, 90-103.

Rubiano, A. M., Carney, N., Chesnut, R., and Puyana, J. C. (2015). Global neurotrauma research challenges and opportunities. Nature 527, S193-S197. doi: 10.1038/nature16035

Saha, B., Jaber, M., Gaillard, A. (2012) Potentials of endogenous neural stem cells in cortical repair. Front. Cell. Neurosci. 6:14. doi: 10.3389/fncel.2012.00014

Saha, B., Peron, S., Murray, K., Jaber, M., and Gaillard, A. (2013). Cortical lesion stimulates adult subventricular zone neural progenitor cell proliferation and migration to the site of injury. Stem Cell Res. 11, 965-977. doi: 10.1016/j.scr.2013.06.006

Sanai, N., Nguyen, T., Ihrie, R. A., Mirzadeh, Z., Tsai, H. H., Wong, M., et al. (2011). Corridors of migrating neurons in the human brain and their decline during infancy. Nature 478, 382-386. doi: 10.1038/nature10487

Sanai, N., Tramontin, A. D., Quinones-Hinojosa, A., Barbaro, N. M., Gupta, N., Kunwar, S., et al. (2004). Unique astrocyte ribbon in adult human brain contains neural stem cells but lacks chain migration. Nature 427, 740-744. doi: 10.1038 /nature02301

Sarnat, H. B. (1995). Ependymal reactions to injury. A review. J. Neuropathol. Exp. Neurol. 54, 1-15. doi: 10.1097/00005072-199501000-00001

Sorensen, J. C., Wanner-Olsen, H., Tonder, N., Danielsen, E., Castro, A. J., and Zimmer, J. (1990). Axotomized, adult basal forebrain neurons can innervate fetal frontal cortex grafts: a double fluorescent tracer study in the rat. Exp. Brain Res. 81, 545-551. doi: 10.1007/BF02423503

Spalding, K. L., Bergmann, O., Alkass, K., Bernard, S., Salehpour, M., Huttner, H. B., et al. (2013). Dynamics of hippocampal neurogenesis in adult humans. Cell 153, 1219-1227. doi: 10.1016/j.cell.2013.05.002

Su, Z., Niu, W., Liu, M. L., Zou, Y., and Zhang, C. L. (2014). In vivo conversion of astrocytes to neurons in the injured adult spinal cord. Nat. Commun. 5, 3338. doi: $10.1038 /$ ncomms 4338

Sullivan, G. M., Mierzwa, A. J., Kijpaisalratana, N., Tang, H., Wang, Y., Song, S. K., et al. (2013). Oligodendrocyte lineage and subventricular zone response to traumatic axonal injury in the corpus callosum. J. Neuropathol. Exp. Neurol. 72, 1106-1125. doi: 10.1097/NEN.0000000000000009

Sun, D., Bullock, M. R., Altememi, N., Zhou, Z., Hagood, S., Rolfe, A., et al. (2010). The effect of epidermal growth factor in the injured brain after trauma in rats. J. Neurotrauma 27, 923-938. doi: 10.1089/neu.2009.1209

Sun, D., Bullock, M. R., McGinn, M. J., Zhou, Z., Altememi, N., Hagood, S., et al. (2009). Basic fibroblast growth factor-enhanced neurogenesis contributes to cognitive recovery in rats following traumatic brain injury. Exp. Neurol. 216, 56-65. doi: 10.1016/j.expneurol.2008.11.011

Sundholm-Peters, N. L., Yang, H. K., Goings, G. E., Walker, A. S., and Szele, F. G. (2005). Subventricular zone neuroblasts emigrate toward cortical lesions. J. Neuropathol. Exp. Neurol. 64, 1089-1100. doi: 10.1097/01.jnen.0000190066.13312.8f

Szele, F. G., and Chesselet, M. F. (1996). Cortical lesions induce an increase in cell number and PSA-NCAM expression in the subventricular zone of adult rats. $J$. Comp. Neurol. 368, 439-454.

Szele, F. G., Dowling, J. J., Gonzales, C., Theveniau, M., Rougon, G., and Chesselet, M. F. (1994). Pattern of expression of highly polysialylated neural cell adhesion 
molecule in the developing and adult rat striatum. Neuroscience 60, 133-144. doi: 10.1016/0306-4522(94)90209-7

Tajiri, N., Kaneko, Y., Shinozuka, K., Ishikawa, H., Yankee, E., McGrogan, M., et al. (2013). Stem cell recruitment of newly formed host cells via a successful seduction? Filling the gap between neurogenic niche and injured brain site. PLoS ONE 8:e74857. doi: 10.1371/journal.pone.0074857

Taylor, S. R., Smith, C., Harris, B. T., Costine, B. A., and Duhaime, A. C. (2013). Maturation-dependent response of neurogenesis after traumatic brain injury in children. J. Neurosurg. Pediatr. 12, 545-554. doi: 10.3171/2013.8.PEDS13154

Teramoto, T., Qiu, J., Plumier, J. C., and Moskowitz, M. A. (2003). EGF amplifies the replacement of parvalbumin-expressing striatal interneurons after ischemia. J. Clin. Invest. 111, 1125-1132. doi: 10.1172/JCI200317170

Theus, M. H., Ricard, J., Bethea, J. R., and Liebl, D. J. (2010). EphB3 limits the expansion of neural progenitor cells in the subventricular zone by regulating p53 during homeostasis and following traumatic brain injury. Stem Cells 28, 1231-1242. doi: 10.1002/stem.449

Thomas, L. B., Gates, M. A., and Steindler, D. A. (1996). Young neurons from the adult subependymal zone proliferate and migrate along an astrocyte, extracellular matrix-rich pathway. Glia 17, 1-14.

Thomsen, G. M., Le Belle, J. E., Harnisch, J. A., McDonald, W. S., Hovda, D. A., Sofroniew, M. V., et al. (2014). Traumatic brain injury reveals novel cell lineage relationships within the subventricular zone. Stem Cell Res. 13, 48-60. doi: $10.1016 /$ j.scr.2014.04.013

Tzeng, S. F., and Wu, J. P. (1999). Responses of microglia and neural progenitors to mechanical brain injury. Neuroreport 10, 2287-2292. doi: 10.1097/00001756199908020-00012

Urban, N., and Guillemot, F. (2014). Neurogenesis in the embryonic and adult brain: same regulators, different roles. Front. Cell. Neurosci. 8:396. doi: $10.3389 /$ fncel.2014.00396

Volpe, J. J. (1995). Neurology of the Newborn, 3rd Edn. Philadelphia, PA: W.B. Saunders \& Company. 431-445.

Wang, C., Liu, F., Liu, Y. Y., Zhao, C. H., You, Y., Wang, L., et al. (2011). Identification and characterization of neuroblasts in the subventricular zone and rostral migratory stream of the adult human brain. Cell Res. 21, 1534-1550. doi: $10.1038 / \mathrm{cr} .2011 .83$

Weickert, C. S., Webster, M. J., Colvin, S. M., Herman, M. M., Hyde, T. M., Weinberger, D. R., et al. (2000). Localization of epidermal growth factor receptors and putative neuroblasts in human subependymal zone. J. Comp. Neurol. 423, 359-372. doi: 10.1002/1096-9861(20000731)423:3<359::AIDCNE1>3.0.CO;2-0

Weinstein, D. E., Burrola, P., and Kilpatrick, T. J. (1996). Increased proliferation of precursor cells in the adult rat brain after targeted lesioning. Brain Res. 743, 11-16. doi: 10.1016/S0006-8993(96)00979-1
Wichterle, H., Garcia-Verdugo, J. M., and Alvarez-Buylla, A. (1997). Direct evidence for homotypic, glia-independent neuronal migration. Neuron 18, 779-791. doi: 10.1016/S0896-6273(00)80317-7

Willis, P., Berry, M., and Riches, A. C. (1976). Effects of trauma on cell production in the subependymal layer of the rat neocortex. Neuropathol. Appl. Neurobiol. 2, 377-388. doi: 10.1111/j.1365-2990.1976.tb00511.x

Wolfe, R. P., Leleux, J., Nerem, R. M., and Ahsan, T. (2012). Effects of shear stress on germ lineage specification of embryonic stem cells. Integr. Biol. (Camb). 4, 1263-1273. doi: 10.1039/c2ib20040f

Yang, D. Y., Chen, Y. J., Wang, M. F., Pan, H. C., Chen, S. Y., and Cheng, F. C. (2010). Granulocyte colony-stimulating factor enhances cellular proliferation and motor function recovery on rats subjected to traumatic brain injury. Neurol. Res. 32, 1041-1049. doi: 10.1179/016164110X12807570 510013

Yoshiya, K., Tanaka, H., Kasai, K., Irisawa, T., Shiozaki, T., and Sugimoto, H. (2003). Profile of gene expression in the subventricular zone after traumatic brain injury. J. Neurotrauma 20, 1147-1162. doi: 10.1089/089771503770 802844

Young, C. C., Brooks, K. J., Buchan, A. M., and Szele, F. G. (2011). Cellular and molecular determinants of stroke-induced changes in subventricular zone cell migration. Antioxid. Redox Signal. 14, 1877-1888. doi: 10.1089/ars.2010.3435

Yu, S. J., Tseng, K. Y., Shen, H., Harvey, B. K., Airavaara, M., and Wang, Y. (2013). Local Administration of AAV-BDNF to subventricular zone induces functional recovery in stroke rats. PLoS ONE 8:e81750. doi: 10.1371/journal.pone.0081750

Zheng, W., ZhuGe, Q., Zhong, M., Chen, G., Shao, B., Wang, H., et al. (2013). Neurogenesis in adult human brain after traumatic brain injury. $J$. Neurotrauma 30, 1872-1880. doi: 10.1089/neu.2010.1579

Zuccotti, A., Le Magueresse, C., Chen, M., Neitz, A., and Monyer, H. (2014). The transcription factor Fezf2 directs the differentiation of neural stem cells in the subventricular zone toward a cortical phenotype. Proc. Natl. Acad. Sci. U.S.A. 111, 10726-10731. doi: 10.1073/pnas.1320290111

Conflict of Interest Statement: The authors declare that the research was conducted in the absence of any commercial or financial relationships that could be construed as a potential conflict of interest.

Copyright (c) 2016 Chang, Adorjan, Mundim, Sun, Dizon and Szele. This is an open-access article distributed under the terms of the Creative Commons Attribution License (CC BY). The use, distribution or reproduction in other forums is permitted, provided the original author(s) or licensor are credited and that the original publication in this journal is cited, in accordance with accepted academic practice. No use, distribution or reproduction is permitted which does not comply with these terms. 